Borstal Institution, though in his group in addition to the correction of cosmetic disfigurements remedial surgery of a more general kind was carried out, such as the treatment of varicose veins, hernia, and congenital morbus cordis.

Successive authorities have echoed Wflliam Healy's dictum" : "It ought to be generally realized, in all common sense, that any physical peculiarities, defects, or diseases of the offender which stand in the way of social success should be as efficiently treated as possible." Everyone would accept that, but when asked to consider the possible causal relationships between these defects and crime we may agree with Sir Norwood East" : "Continuous observation of adolescent and adult offenders not only shows the true relation between the physical abnormality and the crime, but also the importance of caution in determining the association." Neither Lewison nor Ogden offer acceptable control groups, so that uncertainty remains on whether physical disabilities cause crime or whether the correction of them is the specific treatment. But both studies report a notable improvement in the attitude of the offender within the prison- "heightening of morale and relief from hostility . . . interest in learning a trade and manifest desire to change their way of life." Ogden, in particular, recognized and deliberately exploited the psychological elements of the treatment, making the patient participate (by earning his recommendation for treatment), trusting him with some responsibility, transferring him to a warmly accepting environment, and supporting him psychologically after the treatment was over. It is of interest that not only the facial operations but also correction of such mundane disabilities as varicose veins are claimed to improve the attitude.

There is no need to justify the correction of cosmetic and other surgical disabilities in offenders. It is indeed regularly carried out at Grendon Prison in Britain and elsewhere. But these papers give food for thought. Does the change in attitude occur before the operation? Is the whole procedure having its major effect on criminality by changing the offender's relationship with authority ? If so, by what other means could a similar effect be obtained for the benefit of those with straight noses and no varicose veins? Will other dramatic measures to which offenders are submitted ${ }^{6}$ prove to be acting in a similar manner? The final answer will probably be that there may be some short cuts in the correction of chronic offenders, but it is still likely to be a long journey, and mostly uphill.

\section{Temperature Level}

The announcement in the Commons last week by the President of the Board of Trade that Britain is to adopt the metric system of weights and measures ${ }^{1}$ will mainly affect industry and commerce, though he hoped that in time it would become " the primary system of weights and measures for the country as a whole." Medicine still has some way to go before the present anomalies of working with two systems side by side are removed. Since the beginning of 1946 the $\dot{B} . M . \mathcal{F}$. has given a lead to readers in Britain and a translation to those overseas by inserting metric equivalents after every pharmacopoeial dos : and Imperial measurement, and by recording Centigrade temperatures after Fahrenheit.
Meanwhile the new drugs pouring on to the market have made clinicians become increasingly accustomed, with the help of the British National Formulary, to prescribing in metric units. But whether measurements are made in feet and inches or metres and centimetres is still apt to depend on the purpose the medical attendant has in mind, on tradition in a particular field of study, or on personal inclination. And in clinical thermometry perhaps the metric system has so far made less progress than elsewhere in medicine-if the Centigrade scale may be regarded as part of metric measurement. Though the Fahrenhert scale is now an exile from laboratories and is feeling the wind of change in our weather reports, it continues to be used in ward and consulting-room, probably because its inconveniences for many purposes are not noticed there. In fact the smaller size of its degrees is sometimes regarded in Britain as giving it an advantage over the Centigrade scale, though it seems unlikely to withstand in the end the metric advance in this country or common usage in many countries overseas, notably in Europe.

The British Standards Institution has recently issued a draft specification for clinical thermometers which has at least one novelty for medical men in Britain. This is that the mark showing "normal" temperature should be at $98.6^{\circ} \mathrm{F}$. instead of the familiar $98.4^{\circ}$. The convenience of the new level is that it is practically identical with $37^{\circ} \mathrm{C}$. and is the level accepted in Canada, Australia, India, the U.S.A., and on the Continent of Europe.

In contrast to most measurable features of the human body the range of the temperature is remarkably small in health, ${ }^{2}$ though such variations as it does undergo are in response to a great diversity of influences. ${ }^{3-6}$ Among them are reported to be the ambient temperature of the environment, physical activity, emotion, ovulation, age, and sex. In addition the diurnal variation is an obvious feature of hospital charts, and the fact that the temperature differs in different parts of the body such as mouth, axilla, and rectum is a truism of clinical examination. Therefore "the question may be fairly asked," as Samson Wright ${ }^{7}$ put it, "Why have a mark on clinical thermometers opposite $98.4^{\circ} \mathrm{F}$. $\left(36.9^{\circ}\right.$ C.) ?" Probably the convenience of having it somewhere on the scale is too great to forgo, even though it is so imprecise that to shift it to $98.6^{\circ} \mathrm{F}$. will make no difference in practice.

Though rises in the temperature of the human body have excited the attention of diagnosticians since ancient times the founder of clinical thermometry as we know it to-day was C. A. Wunderlich (1815-77), professor of medicine at Leipzig University, whose classic work on the subject appeared in $1868 .^{\circ}$ Of him it has been said that he found

1 Hansard, 24 May 1964.

${ }^{2}$ Pearl, R., Introduction to Medical Biometry and Statistics. 2nd ed. Philadelphia and London. 1930.

${ }^{3}$ Moncrieff, A., and Hussey, B. J., Brit. med. F., 1948, $2,972$.

${ }^{4}$ Grayson, J., Brit. med. F., 1951, 2, 1379.

${ }^{5}$ Pickering, G., Lancet, 1958, 1, 1.

${ }^{6}$ Maddocks, I., and Lovell, R. R. H., Brit. med. F., 1962, 1, 436.

7 Wright, S., ibid., 1949, 1, 610.

- 8 Wunderlich, C. A., Medical Thermometry. 2nd ed., trans. W. B. Woodman. New Sydenham Society, London. 1871.

${ }^{9}$ Garrison, F. H., History of Medicine. 4th ed. Philadelphia. 1929.

${ }^{10} \mathrm{Du}$ Bois, E. F., Fever and the Regulation of Body Temperature. Illinois. 1948.

11 Ivy, A. C., Quart. Bull. Northw. Univ. med. Sch., 1944, 18, 22.

${ }^{12}$ Renbourn, E. T., and Bonsall, F. F., Brit. med. F., 1946, 1, 909.

13 Kleitman, N., and Jackson, D. P., F. appl. Physiol., 1950, 3, 309.

14 Wolf, S., and Wolff, H. G., Arch. intern. Med., 1942, 70, 293.

16 Alvarez, W. C., Gastroenterology, 1945, 5, 320. 
fever a disease and left it a symptom. ${ }^{9}$ He too was impressed by the lability of the temperature within a small range in the healthy person, and subsequent observers have reported from specially collected data a normal rectal temperature as one lying anywhere between $35.7^{\circ}$ C. $\left(96.2^{\circ} \mathrm{F}\right.$.) and $38.1^{\circ}$ C. $\left(100.6^{\circ}\right.$ F.). ${ }^{10}$ A group of 276 medical students in class were found by A. C. Ivy ${ }^{11}$ to have a mean temperature of $98.1^{\circ} \mathrm{F}$. $\left(36.7^{\circ}\right.$ C.) with a range derived from plus or minus twice the standard deviation of $97.7^{\circ} \mathrm{F}$. $\left(36.5^{\circ} \mathrm{C}\right.$.) to $98.5^{\circ} \mathrm{F}$. $\left(36.9^{\circ} \mathrm{C}\right.$. $)$. In special circumstances healthy people have been recorded as having a temperature up to $104^{\circ} \mathrm{F}$. $\left(40^{\circ}\right.$ C. $)$, reports $\mathrm{Du}$ Bois, ${ }^{10}$ but he considers that under ordinary conditions rectal temperatures above $37.5^{\circ} \mathrm{C}$. $\left(99.5^{\circ} \mathrm{F}\right.$.) should be regarded with suspicion. In the tropics it is possible that slightly higher average temperatures are normal, though seasonal variation there has been observed. ${ }^{12}$ Furthermore, N. Kleitman and D. P. Jackson ${ }^{13}$ found in tests on healthy recruits to the U.S. Navy that on the average the higher the body temperature the better the performance. Thus normal temperature can hardly be said to exist; average temperature varies in response to many factors; and optimum temperature may be something we rarely attain.

But in practice medical men are sometimes required to decide a course of action in relation to a temperature whose significance may be in doubt. A patient in a temperate climate whose oral temperature rises every day to between $99^{\circ} \mathrm{F}$. and $100^{\circ} \mathrm{F}$. $\left(37.2^{\circ} \mathrm{C}\right.$. and $37.8^{\circ} \mathrm{C}$.) should certainly be investigated, and sometimes an infective or other specific cause of the rise will be found. But in occasional cases it would seem possible that the patient is healthy, or at least has nothing more alarming than an emotional disturbance. ${ }^{14}{ }^{15}$

\section{Sir Henry Dale 90}

Sir Henry Dale, O.M., will be 90 years old next week-or perhaps we should say 90 years young. Scientists and medical men in many countries will join with their colleagues in Britain in saluting with affection and gratitude the man who has done so much to bring about the medical revolution of our times by his own research and by the inspiration he has been to so many others whose work has been applied in the laboratory and at the bedside of the patient.

When the B.M.F. celebrated his 80 th birthday in its issue of 4 June 1955, Lord Adrian wrote: ". . . He is now regarded by physiologists in every part of the world with the affectionate veneration we reserve for our greatest masters." In the same number Otto Loewi, who shared with Sir Henry the Nobel Prize for medicine in 1936, wrote: "We met for the first time in 1903, in the small and poorly equipped, yet extremely creative and dynamic laboratory of Ernest Starling. Our interests and aspirations had much in common, and before long a close mutual relationship developed, from which emerged our lifelong friendship."

In an autobiographical essay published last year Sir Henry tells how he obtained the Coutts-Trotter Studentship at Trinity College, Cambridge, which became vacant through the departure of Ernest Rutherford on his appointment to the professorship of physics at McGill University. And so he was able to spend two years under Professor J. N. Langley at Cambridge "as an apprentice to physiological research."
And he showed then, as he puts it, that "I had no morbid intolerance of the drudgery which accurate research usually involves." But after the two years were over he felt he should complete his medical course, and he went to St. Bartholomew's Hospital 65 years ago. Then came another choice-of the George Henry Lewes Studentship-which he made in preference to taking the job as a house-physician at Barts that was offered to him. With the studentship he was able to work under Starling in the department of physiology in University College, London. It was towards the end of his tenure of the Lewes Studentship that Dale spent some months in Paul Ehrlich's institute in Frankfurt. Once back in London he obtained the Sharpey Studentship at University College, and then came his appointment to the Wellcome Physiological Research Laboratories. To-day Sir Henry is still a member of the Wellcome Trust and scientific consultant to it. $\mathrm{He}$

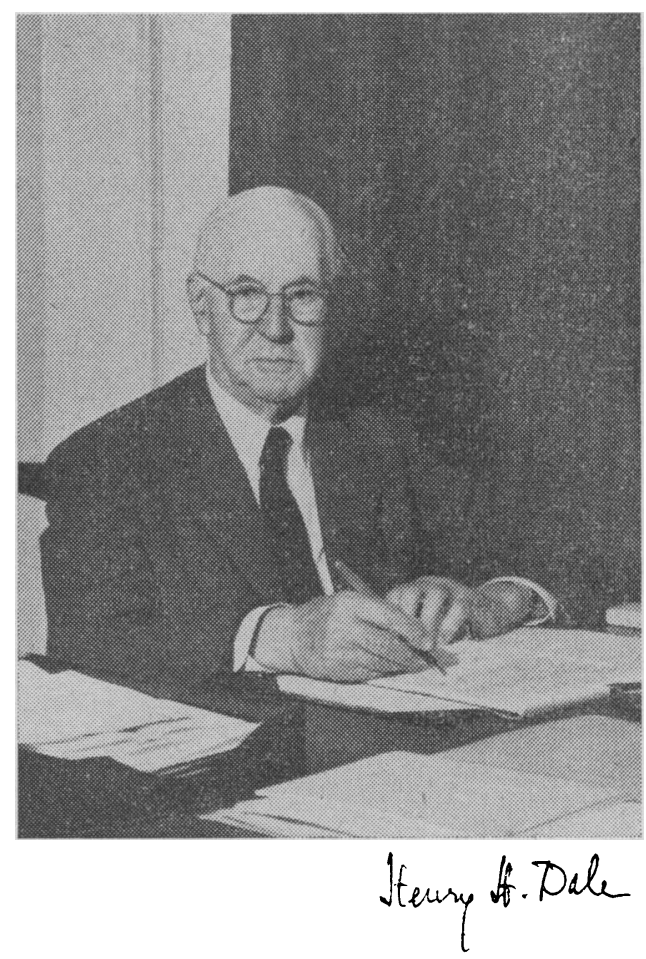

recalls how Mr. Wellcome suggested "that I should try to throw light on the previously obscure pharmacology of ergot. . . ." And thus began what Dr. Herbert Gasser called in our commemorative number of 1955 "the saga of ergot."

The great part played by Sir Henry Dale in medical research since then has been told before, crowned as it was by his appointment as the first Director of the National Institute for Medical Research. And we publish in the middle pages of this week's issue an essay of recognition of his work on histamine by Dr. J. F. Riley. But here on this notable birthday the B.M.F. thought it would be of special interest to touch, however briefly and lightly, upon the early beginnings of a man who has meant so much to medical science, and who has always maintained an intimate contact with clinical medicine and those who practise it.

The British Medical fournal in particular owes Sir Henry Dale a great debt for his never-failing help and advice, now over many years. So we take a special pride and pleasure in joining so many others in sending congratulations to Sir Henry Dale and his wife, who with him celebrated their diamond wedding on 5 November 1964. 